\title{
Laparotomy for Abdominal Injury Indication \& Outcome of patients at a Teaching Hospital in Addis Ababa, Ethiopia
}

\author{
Kirubel Abebe $^{1 *}$ Mahteme Bekele ${ }^{1}$, Ayelign Tsehaye ${ }^{1}$, Befekadu Lemmu ${ }^{1}$, \\ Engida Abebe ${ }^{1}$
}

\footnotetext{
OPEN ACCESS

Citation: Kirubel Abebe Mahteme Bekele, Ayelign Tsehaye, Befekadu Lemmu, Engida Abebe. Laparotomy for Abdominal Injury Indication \& Outcome of patients at a Teaching Hospital in Addis Ababa, Ethiopia. Ethiop J Health Sci.2017;29(4):503.doi: http://dx.doi.org/ 10.4314/ejhs.v29i4.12

Received: March 14, 2019

Accepted: April 25, 2019

Published: July 1, 2019

Copyright: (C) 2019 Kirubel Abebe, et al.

This is an open access article distributed under the terms of the Creative Commons Attribution License, which permits unrestricted use, distribution, and reproduction in any medium, provided the original author and source are credited. Funding: Nil

Competing Interests: The authors declare that this manuscript was approved by all authors in its form and that no competing interest exists.

Affiliation and Correspondence: ${ }^{1}$ University of Health and Allied Sciences- Nursing, Ghana

${ }^{2}$ University of the Western Cape, South Africa-Nursing, Cape Town, Western Cape, South Africa

${ }^{3}$ Mzuzu University-Nursing and Midwifery, Luwinga, Mzungu, Malawi

*Email: Kirunel4@gmail.com
}

\section{ABSTRACT}

BACKGROUND: Abdominal injury is among the major causes of trauma admissions. The aim was to determine etiology, commonly injured organs, indication and outcome of patients with abdominal injuries requiring laparotomy.

METHODS: $A$ retrospective study of all adult patients who underwent laparotomy for abdominal injury at St. Paul's Hospital Millennium Medical College was conducted from January 2014 to December 2016. The factors associated with outcome were identified with bivariate and multivariate logistic regressions.

RESULTS: Laparotomy for abdominal injury was performed for 145 patients. Of these, 129 (89\%) case records were retrieved. The male to female ratio was 6.2:1. The mean age was 29 years, and most of them were unemployed. Penetrating trauma was the commonest injury, stab (46, 35.7\%) and Road Traffic Accidents (RTA) (27, 20.9\%) being the leading causes. Extra-abdominal injuries were seen in $33.3 \%$ (46) of the cases. Hollow organs were commonly injured than solid organs. Small intestine (35, 43.8\%) and Spleen $(17,34.7 \%)$ were the leading injured organs in penetrating and blunt respectively. The main procedure performed was repair of hollow and solid organ laceration/perforation (70,54.3\%). The negative laparotomy rate was $4.6 \%$ (6). Complications were seen in $23(17.8 \%)$ patients, the commonest being irreversible shock (7,30.4\%). The mortality rate was $8.5 \%$ (11), and it was significantly associated with blunt abdominal injury $(A O R=7.25 ; 95 \%$ CI 1.09-48.37; $p=0.041)$ and systolic blood pressure $<90 \mathrm{mmHg}(A O R=8.66 ; 95 \%$ CI 1.1-68.41; $p=0.041)$.

CONCLUSION: Stab and RTA were the commonest indications of laparotomy. The mortality was significantly associated with blunt abdominal injury and hypotension $(S B P<90 \mathrm{mmHg})$.

KEYWORDS: Abdominal injury, Laparotomy, Outcome, Indication

\section{INTRODUCTION}

Trauma is the second largest cause of illness accounting for $16 \%$ of global diseases burden, and it is the highest between the ages of 15 and 45 years.According to $\mathrm{WHO}$, more than $90 \%$ of injuries occur in low and middle-income countries. Africa, mainly sub-Saharan

DOI: http://dx.doi.org/10.4314/ejhs.v29i4.12 
region, contributes $21 \%$ of these (1). The rapid growth of motorized transport and expansion of industrial production without adequate safety precautions is partly blamed for the burden in these areas (2).

The scarce data in Ethiopia on burden of trauma shows increasing rate which accounts for half of surgical emergencies (3-6).

Abdomen is the third commonly injured organ, and 40 to $80 \%$ of deaths after trauma are due to exsanguination caused by injuries to the abdominal organs (7-9). There are different patterns as to the etiology and the type of abdominal injury, most literatures indicate that blunt is the common (85\%) mechanism. Road traffic accidents (RTAs) and stab injuries were the commonest causes of blunt and Penetrating injury respectively (7-10).

According to an Indian study the commonest $(53 \%)$ causes of blunt is road traffic accident. Spleen was the commonest $(53 \%)$ organ injured and the most common surgery performed was splenectomy $(30 \%)$. The mortality rate was $4 \%$ (11). Similarly, a study conducted in Turkish showed RTA being the leading cause $(87.5 \%)$ of a blunt abdominal injury fallowed by a fall from height (9.7\%) and blows (2.8\%) (12).

A Nigeria study done in Gombe Federal Teaching Hospital, penetrating abdominal trauma was seen in the majority $(62.9 \%)$ of patients. Stab $(28.1 \%)$ and road traffic accidents $(30,3 \%)$ were the commonest causes. Spleen $(29.8 \%)$ was the most common isolated injured organ while the small bowel and the colon $(40.7 \%)$ were the most injured in combined trauma. Surgical site infection $(42.9 \%)$ was the leading post-operative complication (13). A study from Kenyatta National Hospital revealed penetrating abdominal injury as the commonest (66.2\%) mechanism. (14).

In contrast to the above, a Tanzanian study revealed blunt abdominal injury as the commonest (77.8\%) mechanism, and RTA being the main cause. The spleen $(75.9 \%)$ and gastrointestinal tract $(10.3 \%)$ were the leading injured organs. Around $58.6 \%$ had laparotomy with a negative laparotomy rate of $7.8 \%$. Complication and mortality rates were $20.7 \%$ and $17.9 \%$ respectively (15). Similarly, a study done in
Uganda revealed that $85.7 \%$ of the patients had blunt abdominal injury; the spleen was injured in $43.7 \%$. Most patients (68.9 \%) were managed nonoperatively (16).

The paper we found on abdominal injuries due to missile injuries in Ethiopia showed a mortality rate of $16.5 \%(17)$. The reports from different parts of Ethiopia showed blunt injuries as the main mechanisms, assaults and RTA being the leading causes $(3,4,5)$.

Management of patients with abdominal injury can be operative (Laparotomy) or nonoperative. Generally, laparotomy is required in about $25 \%$ of abdominal injuries (12). Peritonitis, hemodynamic instability, evisceration and impalement are most common indications for laparotomy. Non-operative management is a standard protocol for hemodynamically stable solid organ injuries with a failure rate of $2-3 \%$. (8$10,15,17,18)$. Scarcity of resources like imaging modalities in developing countries is a major challenge for non-operative management (15).

Conducting this study to determine etiology, commonly injured organs, indication and outcome of patients with abdominal injuries requiring laparotomy will help to evaluate our experience and to analyze the magnitude of the problem. It also helps to compare the pattern with other figures and to design appropriate management outline as well as preventive measures.

\section{METHODS AND SUBJECTS}

This was a facility based retrospective study of all adult patients who underwent laparotomy for abdominal injury at St. Paul's Hospital Millennium Medical College (SPHMMC) from January 2014 to December 2016. SPHMMC is a tertiary level referral and teaching hospital for both under and postgraduate programs. A total of 8 surgeons and seven senior surgical residents (under supervision) were involved in the laparotomies. All adult patients (age $>=15$ ) who underwent laparotomy for abdominal injury in the study period were included. Patients who were referred from other hospitals after trauma laparotomy and patients with incomplete documentation were excluded.

The operating room logbook was used to identify study subjects. Trained final year surgical

DOI: http://x.doi.org/10.4314/ejhs.v29i4.12 
residents collected the data from individual patient's medical records with a pre-tested structured data collection format. Data were checked for completeness, cleaned, entered and analyzed with SPSS version 20. Results were shown using charts, tables, graphs, texts, and central tendency statistics. To determine the association between the dependent and independent variables, statistical analysis and logistic regression of $95 \% \mathrm{CI}$ and odds ratio were used. To minimize the effect of confounder variables, the association at bivariate logistic regression with a p-value $<0.3$ was entered into a multivariate logistic regression model, and $\mathrm{p}<0.05$ was used as statistically significant.

\section{RESULTS}

Totally, 2776 emergency surgeries were done during the study period; among this 2214 were laparotomies. Trauma accounted for $15.3 \%$ $(n=425)$ of emergency procedures. Laparotomy for abdominal injury contributed $34 \%(n=145)$ of trauma procedures and it was the third $(145,6.5$ $\%$ ) leading cause of emergency laparotomy following appendicitis and large bowel obstruction. Of these, records of 129 patients were analyzed.

Males were commonly affected with a male-tofemale ratio of 6.2:1. The most commonly affected age group was 20-29 years $(n=48$, $37.2 \%$ ), and the mean was 29 years. Regarding marital status, $52.7 \%(\mathrm{n}=68)$ were single. Most of the patients, $68 \%(\mathrm{n}=80)$, lived in rural areas. Occupation distribution showed unemployed $(n=34)$, students $(n=32)$, and farmers $(n=26)$ accounted for $71.4 \%$ of all.

Penetrating abdominal injury was the leading indication for trauma laparotomy $(n=80,62 \%)$. Overall, the leading cause of abdominal injury was stab $(35.7 \%)$. RTA was the major $(n=27,55.1 \%)$ cause of blunt abdominal injuries.
Table 1: Socio-demographic characteristics of Patients treated with laparotomy for abdominal injury at SPHMMC, Addis Ababa, 2019

\begin{tabular}{|lcc|}
\hline Variables & Frequency(n=129) & $\mathbf{\%}$ \\
\hline Age in Years & 27 & 20.9 \\
$<20$ & 48 & 37.2 \\
$20-29$ & 33 & 25.6 \\
$30-39$ & 13 & 10.1 \\
$40-49$ & 4 & 3.1 \\
$50-59$ & 4 & 3.1 \\
$\geq 60$ & & \\
Sex & 111 & 86.0 \\
Male & 18 & 14.0 \\
Female & & \\
Marital Status & 59 & 45.7 \\
Married & 68 & 52.7 \\
Single & 2 & 1.6 \\
Divorced & & \\
Residence & 49 & 38 \\
Urban & 80 & 62 \\
Rural & & \\
Educational Status & 32 & 24.8 \\
No Formal Education & 51 & 39.5 \\
Primary Education & 46 & 35.7 \\
High School \& Above & & \\
Occupation & & 26.4 \\
Unemployed & 34 & 24.8 \\
Student & 32 & 7 \\
Farmer & 26 & 6.2 \\
Trader & 9 & 5.4 \\
Office worker & 8 & 3.9 \\
Housewife & 7 & 3.1 \\
Driver/Assistant & 5 & 3.1 \\
Daily laborers & 4 & \\
Others & 4 & \\
\hline
\end{tabular}

Table 2: Types and causes of abdominal injury in patients treated with laparotomy at SPHMMC, Addis Ababa, 2019

\begin{tabular}{|lcc|}
\hline Type of injury & Frequency & $\mathbf{\%}$ \\
\hline Blunt & $\mathbf{4 9}$ & $\mathbf{3 8}$ \\
RTA & 27 & 20.9 \\
Falls & 14 & 10.9 \\
Assaults & 8 & 6.2 \\
Penetrating & $\mathbf{8 0}$ & $\mathbf{6 2}$ \\
Stab & 46 & 35.7 \\
Gunshot & 33 & 25.6 \\
Horn & 1 & 0.8 \\
\hline
\end{tabular}


The average duration from injury to presentation was $16.7 \mathrm{hrs}$ and nearly half of the patients $(\mathrm{n}=63,48.8 \%)$ presented within 6 hours after injury. Less than half $(n=33,41 \%)$ of pateints who live in rural setting came within 6 hrs of injury.

Extra-abdominal injuries were seen in 33.3 $\%(n=43)$ of the patients. The commonest was chest injury $(\mathrm{n}=31,72 \%)$ followed by Fracture $(n=9,20 \%)$ and head injury $(n=3,7 \%)$. They were more common in penetrating injury than blunt $(36.2 \%$ vs $28 \%)$.

The majority of patients $(n=100,77.5 \%)$ had deranged vital signs at the time of presentation. Of these, $18.6 \%(n=24)$ had both hypotension and tachycardia with a $33.3 \%$ chance of death. Patients with penetrating abdominal injury who presented with deranged vital signs had a better outcome than similar patients with blunt injury ( $50 \%$ vs. $21.4 \%)$.

Table 3: Vital sign at presentation and patient outcome in abdominal injury requiring laparotomy at SPHMMC, Addis Ababa, 2019

\begin{tabular}{|lccccc|}
\hline \multirow{2}{*}{ Mechanism } & \multicolumn{2}{c}{$\mathrm{SBP}>=90 \mathrm{mmHg}$} & \multicolumn{2}{c|}{$\mathrm{SBP}<90 \mathrm{mmHg}$} & Total \\
\cline { 2 - 5 } & Discharged & Died & Discharged & Died & \\
\hline Blunt & 37 & 2 & 5 & 5 & 49 \\
Penetrating & 65 & 1 & 11 & 3 & 80 \\
Total & $\mathbf{1 0 2}$ & $\mathbf{3}$ & $\mathbf{1 6}$ & $\mathbf{8}$ & $\mathbf{1 2 9}$ \\
\hline
\end{tabular}

Perioperative transfusion was required in 36.4 $\%(n=47)$ of the patients, and the need of transfusion was higher in blunt than penetrating injury ( $46.9 \%$ vs. $30 \%)$.

The 129 patients had a total of 208 intrabdominal injuries. Most patients $(n=70$, $54.2 \%$ ) had single organ injury, and in 53(41.1\%) of the patients, the injury involved more than one organ. The negative laparotomy (no intraabdominal organ injury) rate was $4.7 \%(n=6)$. Hollow organs were injured two times than solid organs. The leading injured organs were small intestine $(n=48)$, followed by colon $(n=38)$ and liver $(n=32)$ irrespective of the mechanism of injury. Spleen $(n=17,22.7 \%)$ and small intestine $(n=35,26 \%)$ were the commonly injured organs in blunt and penetrating respectively.

Irrespective of the type of injury, the leading injured single (isolated) organ was the small intestine $18.6 \%(\mathrm{n}=24)$.

The majority of the patients $(n=70,54.3 \%)$ underwent repair of laceration/perforation involving hollow and solid organs. Most of the splenic injuries were managed with splenectomy $(\mathrm{n}=11,55 \%)$, and the remaining were either repaired or spontaneous stoppage of bleeding. Splenectomy was done in all patients with blunt splenic injuries in contrast to penetrating splenic injuries in which the rate of splenectomy was $66.6 \%$.

Regarding combined injuries, most were caused by penetrating injury rather than blunt $(62.3 \%$ vs.37.7\%). The commonly injured organ in association with other intra-abdominal organs was the bowel. It was involved in $62 \%(n=33)$ of the combined injuries. Both the small bowel and the colon were equally injured.

Overall complication occurred in $17.8 \%$ $(n=23)$ of patients and the commonest was irreversible shock (30.4\%).The rate of complication was higher in blunt injuries $(22.4 \%)$ than penetrating $(15 \%)$. The rate of irreversible shock was higher in patients with blunt abdominal injuries $(10.2 \%$ vs. $2.5 \%)$. Enterocutaneous fistula entirely occurred in patients with penetrating abdominal injury and the rate was $3.75 \%$. 
Table 4: Injured organs (isolated and overall), procedures applied (isolated and overall) and mechanism of injury in patients treated with laparotomy for abdominal injury at SPHMMC, Addis Ababa, 2019

\begin{tabular}{|c|c|c|c|c|}
\hline \multirow[t]{2}{*}{ Variables } & \multicolumn{2}{|c|}{ Mechanism } & \multirow[t]{2}{*}{ Total } & \multirow[t]{2}{*}{$\%$} \\
\hline & Blunt & Penetrating & & \\
\hline \multicolumn{5}{|l|}{ Isolated injured organ } \\
\hline Combined & 20 & 33 & 53 & 41.1 \\
\hline Small bowel & 8 & 16 & 24 & 18.6 \\
\hline Spleen & 11 & 2 & 13 & 10.1 \\
\hline Colon & 2 & 10 & 12 & 9.3 \\
\hline Liver & 2 & 4 & 6 & 4.7 \\
\hline No injury & 2 & 4 & 6 & 4.7 \\
\hline Stomach & 0 & 5 & 5 & 3.9 \\
\hline RPH & 0 & 3 & 3 & 2.3 \\
\hline Diaphragmatic injury & 1 & 2 & 3 & 2.3 \\
\hline Genitourinary injury & 2 & 1 & 3 & 2.3 \\
\hline Mesentery & 1 & 0 & 1 & .8 \\
\hline Total & 49 & 80 & 129 & 100.0 \\
\hline \multicolumn{5}{|c|}{$\begin{array}{l}\text { Overall injured organ (one or more in } \\
\text { one patient) }\end{array}$} \\
\hline Small Intestine & 13 & 35 & 48 & 37.2 \\
\hline Colon & 11 & 27 & 38 & 29.5 \\
\hline Liver & 13 & 19 & 32 & 24.8 \\
\hline Stomach & 4 & 17 & 21 & 16.3 \\
\hline Spleen & 17 & 3 & 20 & 15.5 \\
\hline Diaphragm & 1 & 13 & 14 & 10.9 \\
\hline RPH & 5 & 6 & 11 & 8.5 \\
\hline Mesentery & 3 & 6 & 9 & 7 \\
\hline Urinary Bladder & 4 & 2 & 6 & 4.7 \\
\hline Kidney & 2 & 2 & 4 & 3.1 \\
\hline Gallbladder & 0 & 2 & 2 & 1.6 \\
\hline Ureter & 0 & 1 & 1 & 0.8 \\
\hline Pancreas & 2 & 0 & 2 & 1.6 \\
\hline \multicolumn{5}{|l|}{ Isolated Procedures Applied } \\
\hline Repair & 26 & 62 & 62 & 48.1 \\
\hline Resection \& Anastomosis & 4 & 15 & 19 & 14.7 \\
\hline Combined procedures & 3 & 12 & 15 & 11.6 \\
\hline Splenectomy & 9 & 0 & 9 & 7 \\
\hline Colostomy & 0 & 9 & 9 & 7 \\
\hline None & 3 & 6 & 9 & 7 \\
\hline Damage Control & 2 & 1 & 3 & 2.3 \\
\hline Lavage & 2 & 1 & 3 & 2.3 \\
\hline Total & 49 & 80 & 129 & 100 \\
\hline \multicolumn{5}{|l|}{$\begin{array}{l}\text { Overall Procedures Applied } \\
\text { (one or more in one patient) }\end{array}$} \\
\hline Repair & 29 & 41 & 70 & 54.3 \\
\hline Resection \& Anastomosis & 4 & 22 & 26 & 20.2 \\
\hline Colostomy & 1 & 18 & 19 & 14.7 \\
\hline Splenectomy & 11 & 0 & 11 & 8.5 \\
\hline None & 3 & 6 & 9 & 7 \\
\hline Damage Control & 2 & 1 & 3 & 2.3 \\
\hline Lavage & 2 & 1 & 3 & 2.3 \\
\hline Cholecystectomy & 0 & 2 & 2 & 1.5 \\
\hline Ileostomy & 0 & 1 & 1 & 0.8 \\
\hline
\end{tabular}

DOI: http://dx.doi.org/10.4314/ejhs.v29i4.12 
Table 5: Complications, outcome and mechanism of injury of patients requiring laparotomy for abdominal injury at SPHMMC, Addis Ababa, 2019

\begin{tabular}{lcccc}
\hline \multicolumn{1}{c}{ Variables } & \multicolumn{2}{c}{ Mechanism } & Total & \\
\cline { 2 - 3 } & Blunt & Penetrating & & \\
\hline Complications & 2 & 2 & 4 & 3.1 \\
SSI & 0 & 3 & 3 & 2.3 \\
Enterocutaneous Fistula & 1 & 0 & 1 & 0.8 \\
Intra-abdominal collection & 3 & 1 & 4 & 3.1 \\
Burst Abdomen & 5 & 2 & 7 & 5.4 \\
Irreversible Shock & 0 & 1 & 1 & 0.8 \\
HAP & 0 & 1 & 1 & 0.8 \\
DVT & 0 & 1 & 1 & 0.8 \\
Necrotizing Fasciitis & 0 & 1 & 1 & 0.8 \\
Anastomosis site narrowing & & & & \\
Outcome & 42 & 76 & 118 & 91.5 \\
Improved & 7 & 4 & 11 & 8.5 \\
Died & & & & \\
\hline
\end{tabular}

The average post-operative period was 8.3 days, and most $(57.4 \%)$ of the cases stayed for one week. Overall mortality rate was $8.5 \%(\mathrm{n}=11)$ and most $(\mathrm{n}=7,63.6 \%)$ of them had blunt abdominal injury. Mortality was higher in patients who had Extra-abdominal injuries (16.2\% vs. $4.7 \%$ ).

Associated factors with early presentation: In the binary logistic regression analysis, residence of participants, mechanism of injury, associated injury and small bowel injury were significantly associated with early presentation after injury. However, only mechanism of injury: penetrating injury $(\mathrm{AOR}=3.95 ; 95 \%$ CI $1.69-9.23 ; \mathrm{p}=0.002)$ and small bowel injury (AOR $=2.33 ; 95 \%$ CI 1.01$5.39 ; \mathrm{p}=0.047)$ remained significantly associated in the multiple logistic regression analysis.

Associated factors with outcome: The multiple logistic regression analysis identified blunt abdominal injury $(\mathrm{AOR}=7.25 ; 95 \%$ CI 1.09-48.37; $\mathrm{p}=0.041)$ and $\mathrm{SBP}<90 \mathrm{mmHg}(\mathrm{AOR}=8.66 ; 95 \% \mathrm{CI}$ $1.1-68.41 ; p=0.041)$ to be significantly associated with high mortality rate. However, on bivariate analysis, associated injury and transfusion were significantly associated with poor outcome (death).

\section{DISCUSSION}

The burden of trauma at SPHMMC showed the condition to be among the common indications for emergency surgical admissions. The burden is similar to reports in Ethiopia which ranged from
$11.5 \%-70 \%$ (4-6). Studies from Nigeria and Kenya had a higher rate of trauma burden than ours $(12,13)$. This difference could be due to the hospital setting and risk factors for trauma. The abdomen was the third most frequently injured region, and studies showed that the burden ranges from $1 \%-14.2 \%(12,15,16,19)$.

In agreement with other studies, abdominal injuries were more common in males and affect the younger age group. This might be due to male's engagement in high-risk activities and the young age groups being the mobile population more involved in recreational activities $(4,11,13$ 16,20,21). Two-third of the patients in this study were unemployed, farmers and students. This is consistent with Ethiopian, Nigerian, Ugandan and Tanzanian studies $(6,13,15,16)$. Studies reported that abdominal trauma is more prevalent in people with low socioeconomic status which is also seen in our study $(15,22)$.

Penetrating trauma was the leading mechanism of abdominal injury in our study which is in agreement with studies from Kashmir, Uganda, Nigeria and Kenya $(13,14,16,23)$. In contrast to this, Nigerian, Tanzania, Turkish and Australian authors found that blunt injury is more common than penetrating $(12,15,19,22)$. This might reflect a difference in the political situation, effectiveness of traffic law, prevalence of social conflict, countrys' level of growth; in our study, only patients who needed laparotomy were

DOI: http://dx.doi.org/10.4314/ejhs.v29i4.12 
Table 6: Bivariate and multivariate out put on factors affecting duration of presentation \& outcome of patients who underwent laparotomy for abdominal injury at SPHMMC, Addis Ababa, 2019

\begin{tabular}{|c|c|c|c|c|}
\hline \multirow[t]{2}{*}{ Variables } & \multicolumn{2}{|c|}{$\begin{array}{l}\text { Early presentation } \\
\text { (within 6hrs) }\end{array}$} & \multirow{2}{*}{$\begin{array}{l}\text { Bivariate analysis } \\
\text { COR(CI) }\end{array}$} & \multirow{2}{*}{$\begin{array}{l}\text { Multivariate analysis AOR } \\
\text { (CI) }\end{array}$} \\
\hline & Yes & No & & \\
\hline \multicolumn{5}{|l|}{ Residency } \\
\hline Urban & 30 & 19 & $2.2(1.08-4.65) *$ & \\
\hline Rural & 33 & 47 & 1 & \\
\hline \multicolumn{5}{|l|}{ Mechanism } \\
\hline Blunt & 16 & 33 & 1 & 1 \\
\hline Penetrating & 47 & 33 & $2.94(1.39-6.19) * *$ & $3.95(1.69-9.23) * *$ \\
\hline \multicolumn{5}{|c|}{ Associated injury } \\
\hline Yes & 27 & 16 & $2.34(1.11-4.97) *$ & \\
\hline No & 36 & 50 & 1 & \\
\hline \multicolumn{5}{|c|}{ Small bowel injury } \\
\hline Yes & 18 & 30 & 1 & 1 \\
\hline No & 45 & 36 & $2.08(1.004-4.325) *$ & $2.33(1.01-5.39) *$ \\
\hline \multicolumn{5}{|c|}{ Diaphragm injury } \\
\hline yes & 9 & 5 & 2.03(.64-6.44) & \\
\hline \multirow[t]{3}{*}{ No } & 54 & 61 & 1 & \\
\hline & Out & & & \\
\hline & Yes & No & & \\
\hline \multicolumn{5}{|l|}{ Mechanism } \\
\hline Blunt & 7 & 42 & $3.17(.88-11.45)$ & $7.25(1.09-48.37) *$ \\
\hline Penetrating & 4 & 76 & 1 & 1 \\
\hline \multicolumn{5}{|l|}{ SBP } \\
\hline$<90 \mathrm{mmHg}$ & 8 & 16 & $17(4.076-70.88) * * *$ & $8.66(1.1-68.41) *$ \\
\hline$>=90 \mathrm{mmHg}$ & 3 & 102 & 1 & 1 \\
\hline \multicolumn{5}{|c|}{ Associated injury } \\
\hline Yes & 7 & 36 & $3.99(1.1-14.47) *$ & \\
\hline No & 4 & 82 & 1 & \\
\hline \multicolumn{5}{|l|}{ Transfusion } \\
\hline Yes & 9 & 38 & $9.47(1.95-45.99) * *$ & \\
\hline No & 2 & 80 & 1 & \\
\hline \multicolumn{5}{|l|}{ Liver Injury } \\
\hline Yes & 5 & 27 & $2.81(.79-9.92)$ & \\
\hline No & 5 & 88 & 1 & \\
\hline \multicolumn{5}{|l|}{ RPH } \\
\hline Yes & 2 & 9 & $2.69(.504-14.39)$ & \\
\hline No & 9 & 109 & 1 & \\
\hline \multicolumn{5}{|c|}{ Small bowel injury } \\
\hline Yes & 6 & 42 & $2.17(.63-7.54)$ & \\
\hline No & 5 & 76 & 1 & \\
\hline \multicolumn{5}{|l|}{ Colon injury } \\
\hline Yes & 6 & 32 & $2.03(.64-6.44)$ & \\
\hline No & 5 & 88 & 1 & \\
\hline
\end{tabular}

*Significantly associated at $p$-value $<0.05, * *$ significantly associated at $p$-value $<0.005$

Included (blunts tend to be managed conservatively than penetrating). Nigerian and Kenya studies reported that stab, gunshot and RTA were the three leading causes of abdominal injury which holds true for our cases $(13,14)$.
RTA remained the most common cause of blunt abdominal injury which agrees with African and Western authors' findings (11-16,19,21,22). Motorcycle accidents were common in places where motorcycles are used as a major means of

DOI: http://dx.doi.org/10.4314/ejhs.v29i4.12 
transport $(16,24)$. Our study also identified the majority of penetrating injuries occurred in the rural than urban areas (63.85 vs. 36.2) gunshot being the commonest $(75.8 \%)$. This can be explained by illegal owning of unlicensed firearms in the household by the farmers. Among blunt injuries, RTA was more common in urban settings. This might be due to the quality of the roads, the increase traffic jam, increase in the number of motor vehicles, use of mind-altering agents like alcohol and decreased awareness of traffic law $(15,24)$.

Extra-abdominal injuries were quite common in our and other studies.(11,13-16,20,25). The common areas were thorax, head and extremities $(11,14,16,20)$.Mortality was found to be higher in those with extra-abdominal injury which agrees with other studies $(11,13-15)$. The reason could be due to overlooked abdominal injuries, delayed physical findings from altered mentation and increased bleeding resulting in early decompensation.

As reported by Ugandan and Kenyan studies, most of our patients presented within the first 6 hrs of injury $(14,16)$. The study also identified that the mechanism of injury was significantly associated $(\mathrm{p}>0.005)$ with an early presentation, i.e. patients with penetrating injury present earlier than blunt injuries. This can be explained by visible bleeding and evisceration seen more in penetrating injury which could urge the patients to seek care early unlike blunt injuries. The organs involved also seen to be significantly associated $(\mathrm{P}>0.05)$ and odds of early presentation were two times in patients without small bowel injury than with small bowel injury. This may be explained as patients with small bowel injury may be minimally symptomatic until they develop peritoneal irritation. In our study, residence in rural areas were associated with delayed presentation. This could be due to lack of infrastructures and delayed referral from primary health facilities. In contrast to our study, the Kenyan study found that there was no difference between the type of injury and the time taken prior to presentation (14). Literatures from Tanzania and Saudi Arabia agreed that early presentation reduces mortality \& morbidity due to early intervention $(15,26)$.
Our study revealed higher chance of death in patients presented with deranged vital signs. This is consistent with Kenyan and South African literatures $(14,20)$. Holmes, James F. et al in their study mentioned hypotension as a predictor for laparotomy, $11.9 \%$ their patients had hypotension (21). This lesser rate could be due to the wellestablished trauma management protocol.

Overall, the leading injured organs were small bowel, colon and liver. If an isolated injury is considered, small bowel and spleen were the commonly involved organs. With regard to the mechanism, again, the commonly injured organs were small bowel and spleen in penetrating and blunt injury respectively. Different literatures had a variety of findings but most agreed that small bowel commonly is injured in penetrating trauma due to its anatomy (freely mobile and occupies a large area) $(11,13,21)$. They are also consistent with this study concerning the commonest injured organ in blunt mechanism i.e. spleen $(11,16,15,12,13,14,23)$. Overall, in this study, colonic injury was the second commonly injured viscus which is in line with Australian and USA studies, $31 \%$ and $30.2 \%$ respectively $(22,27)$. Injuries to other solid organs such as kidney and pancreases were rare as seen in our study and other studies (20).

The majority of patients underwent a single procedure, and the commonly applied procedure was repair of laceration/perforation of hollow or solid organ which is in agreement with other reports $(12,13,15,21)$. One-half of splenic injuries were managed with splenectomy, and rate tended to be higher in patients with blunt injury. Studies reported the rate of splenectomy to be $30.4 \%-98$ $\%(11,13,15)$. This difference may be due to a high prevalence of blunt injuries, unlike this study. Currently, splenic injury management is shifting toward non-operative treatments due to improvement in patient selection and setup (28). Damage control laparotomy is a potentially lifesaving procedure with the potential to mitigate the devastating clinical outcomes (29). In this study, damage control done in 3 patients and 2 survived.

Literatures reported that negative laparotomy rate ranged from $7 \%-16.1 \%(14,15,20,25)$. Our study has a lower rate than these studies. The difference could be due to improvement in patient

DOI: http://x.doi.org/10.4314/ejhs.v29i4.12 
selection and availability of staff and facilities. Our study also identified that $12 \%$ of patients with stab underwent unnecessary laparotomy which could have been managed conservatively. In contrast, all gunshot laparotomies had findings, and at least one procedure was done. Conservative management for stab wounds tends to be more effective than gunshot with close follow-up and monitoring (18). In our study, hollow organs are injured more than solid organs which is in contrast to studies in Ugandan, Nigeria and Kashmir $(13,16,23)$. This could be explained by the higher prevalence of penetrating injury than blunt.

The overall complication rate was similar with results of studies conducted in Tanzania and Kenya $(14,15)$. Irreversible shock and surgical site infection were reported as common complications elsewhere $(11,13,15,23)$. The rate of surgical site infection ranged from $13 \%$ to $42.9 \%(11,13,15)$. In our study, enterocutaneous fistula entirely occurred in patients with penetrating injury. This could be due to missed perforations which were commonly seen in penetrating than blunt, and the rate was similar with studies from Kashmir and Tanzanian $(15,23)$.

Literatures reported that the mortality rate in abdominal injury ranged from $7.9 \%-16.5 \%$ which is consistent with our study (8.5\%) $(13,17,14,23,30)$. Hypotension and blunt abdominal injury were significantly associated with mortality $(\mathrm{P}<0.05)$. Patients with hypotension had eight times more increased mortality than patients with normal blood pressure. Also, patients with blunt abdominal injury had seven times risk of death than cases with penetrating injury. Other studies also confirmed similar association(14,15). This finding implicates that adequate resuscitation is crucial before rushing to operation theater. Road traffic accident attributed $45.5 \%$ of deaths among the different cause of abdominal injury. This is also seen in another study in Addis Ababa (3).

In conclusion, laparotomy for abdominal injury was among the commonly performed emergency procedures. It was common among young age, male sex and unemployed groups. Stab and RTA were the commonest indications of laparotomy. The negative laparotomy rate for gunshot wounds was nil. It was higher in stab wounds than blunt injuries. Mortality was significantly associated with blunt abdominal injury and hypotension ( $\mathrm{SBP}<90 \mathrm{mmHg}$ ).

This study may not indicate the whole magnitude of problem in the country as the study was done in a single tertiary level hospital. Further multicentric studies need to be conducted for more conclusions. Additionally, it would be better if the mode of arrival was included so as to improve the emergency response system infrastructure such as transportations. However, the study provided local data that can indicate the magnitude of the problem and can be an input for planning preventive strategies plus developing treatment guidelines.

Our study recommends measures like early diagnosis, timely initiation of aggressive resuscitation and recognition of extra-abdominal injuries has a great impact in reducing mortality and morbidity due to abdominal injury. Establishment of effective preventive strategies against RTA and assaults also play a pivotal role in decreasing mortality $\&$ morbidity.

\section{REFERENCES}

1. World health organization. The global burden of disease. 2008.

2. Nordberg E. Injuries as a public health problem in sub-Saharan Africa: epidemiology and prospects for control. East African medical journal. 2000 Dec; 77(12 Suppl): S1-43.

3. Tsegaye F, Abdella K, Ahmed E, Tadesse T, Bartolomeos K. Pattern of Fatal Injuries in Addis Ababa, Ethiopia: A One-year Audit. East and Central African Journal of Surgery 2010;15(2):107.

4. Osman M, Kebede Y, Anberbir S. Magnitude and pattern of injuries in North Gondar Administrative zone, North West Ethiopia. Ethiop Med J. 2003; 41:213-20.

5. Woldemichael K, Berhanu N. Magnitude and pattern of injury in Jimma University specialized hospital, South West Ethiopia. Ethiopian journal of health sciences. 2011;21(3).155-65.

6. Bashah DT, Dachew BA, Tiruneh BT. Prevalence of injury and associated factors among patients visiting the Emergency Departments of Amhara Regional State Referral Hospitals, Ethiopia: a cross-sectional study. Bmc emergency medicine. 2015 Aug 25;15(1):20. 
7. Mattox k, Moor E, Feliciano E. Trauma.McGrawHill;2013

8. Burch JM, Franciose RJ, Moore EE. Trauma. In: Brunucardi FC, editor. Principles of surgery. Vol. 2, New York: McGraw Hill; 2005. p. 129-87.

9. Van der Vlies CH, Olthof DC, Gaakeer M, Ponsen $\mathrm{KJ}$, van Delden OM, Goslings JC. Changing patterns in diagnostic strategies and the treatment of blunt injury to solid abdominal organs. International journal of emergency medicine. 2011 Dec;4(1):47.

10. Petrowsky H, Raeder S, Zuercher L, Platz A, Simmen HP, Puhan MA, Keel MJ, Clavien PA. A quarter century experience in liver trauma: a plea for early computed tomography and conservative management for all hemodynamically stable patients. World journal of surgery. 2012 Feb $1 ; 36(2): 247-54$

11. Mehta N, Babu S, Venugopal K. An experience with blunt abdominal trauma: evaluation, management, and outcome. Clinics and practice. 2014 Jun 18;4(2).

12. Karamercan A, Yilmaz TU, Karamercan MA, Aytaç B. Blunt abdominal trauma: evaluation of diagnostic options and surgical outcomes. ULUSAL TRAVMA VE ACIL CERRAHI DERGISI. 2008 Jul 1;14(3):205.

13. Adejumo AA, Thairu Y, Egenti N. Profile of abdominal trauma in federal teaching hospital, Gombe, North-east, Nigeria: A cross sectional study. Int J Innov Med Health Sci 2015; 4: 41-5.

14. Musau P, Jani PG, Owillah FA. Pattern and outcome of abdominal injuries at Kenyatta National Hospital, Nairobi. East African medical journal. 2006;83(1):37-48.

15. Chalya PL, Mabula JB. Abdominal trauma experience over a two-year period at a tertiary hospital in northwestern Tanzania: a prospective review of 396 cases. Tanzania journal of health research. 2013;15(4).

16. Ruhinda G, Kyamanywa P, Kitya D, Bajunirwe F. Abdominal injury at Mbarara regional referral hospital, Uganda. East and Central African Journal of Surgery. 2008;13(2):29-36.

17. Tegegne A. Abdominal missile injuries at Gonder Hospital, northwestern Ethiopia. Ethiopian medical journal. 1991 Apr;29(2):81-6.

18. Nagy K, Roberts R, Joseph K, An G, Barrett J. Evisceration after abdominal stab wounds: is laparotomy required? The Journal of trauma. 1999 Oct;47(4):622-4.

19. Asuquo M, Nwagbara V, Umoh M, Ugare G, Agbor C, Japhet E, Ikpeme A. Blunt abdominal trauma in a teaching hospital, Calabar, Nigeria. International Journal of Clinical Medicine. 2012 Dec 18;3(07):693.

20. Howes N, Walker T, Allorto NL, Oosthuizen GV, Clarke DL. Laparotomy for blunt abdominal trauma in a civilian trauma service: general surgery. South African Journal of Surgery. 2012 May 1;50(2):30-2.

21. Holmes JF, Wisner DH, McGahan JP, Mower WR, Kuppermann N. Clinical prediction rules for identifying adults at very low risk for intraabdominal injuries after blunt trauma. Annals of emergency medicine. 2009 Oct 31;54(4):575-84.

22. Smith J, Caldwell E, D'Amours S, Jalaludin B, Sugrue M. Abdominal trauma: a disease in evolution. ANZ journal of surgery. 2005 Sep 1;75(9):790-4.

23. Lone GN, Peer GQ, Warn AK, Bhat AM, Warn NA. An experience with abdominal trauma in adults in Kashmir. JK Pract. 2001; 8:225-30

24. Chalya PL, Mabula JB, Dass RM, Mbelenge N, Ngayomela IH, Chandika AB, Gilyoma JM. Injury characteristics and outcome of road traffic crash victims at Bugando Medical Centre in Northwestern Tanzania. Journal of trauma management \& outcomes. 2012 Feb 9;6(1):1.

25. Cox EF. Blunt abdominal trauma. A 5-year analysis of 870 patients requiring celiotomy. Annals of surgery. 1984 Apr;199(4):467.

26. Al-Qahtani MS. The pattern and management outcomes of splenic injuries in the Assir region of Saudi Arabia. West African journal of medicine. 2004;23(1):1-6.

27. Williams MD, Watts D, Fakhry S. Colon injury after blunt abdominal trauma: results of the EAST Multi-Institutional Hollow Viscus Injury Study. Journal of Trauma and Acute Care Surgery. 2003 Nov 1;55(5):906-12.

28. Chalya PL, Mabula JB, Giiti G, Chandika AB, Dass RM, Mchembe MD, Gilyoma JM. Splenic injuries at Bugando Medical Centre in northwestern Tanzania: a tertiary hospital experience. BMC Research notes. 2012 Jan 23;5(1):59.

29. Wang SY, Liao CH, Fu CY, Kang SC, Ouyang $\mathrm{CH}$, Kuo IM, Lin JR, Hsu YP, Yeh CN, Chen SW. An outcome prediction model for exsanguinating patients with blunt abdominal trauma after damage control laparotomy: a retrospective study. $B M C$ surgery. 2014 Apr 28;14(1):24.

30. Udoeyop UW, Iwatt AR. Abdominal trauma in south-eastern Nigeria. Central African journal of medicine. 1991 Dec 1;37(12):409-15. 